\title{
Modeling the spring blooms of ciliates in a deep lake
}

\author{
Onur Kerimoglu • Dietmar Straile • \\ Frank Peeters
}

\begin{abstract}
In contrast to the macro/mesozooplankton, microzooplankton has received much less attention in ecosystem models. In many modeling studies, microzooplankton has been either entirely neglected, or else, data were often not available for validation, or agreement between the observed and the simulated abundances was rather poor. In this study, we compare the simulation results from several alternative models considering different formulations of ciliate growth in a hydrodynamically driven $1 \mathrm{D}$ nutrient-phytoplankton multiple zooplankton model, with long-term datasets from the deep, monomictic Lake Constance. We show that the parameterization of the limitation of ciliate growth with a constant specific mortality rate and/or predation by copepods leads to uncontrolled ciliate blooms. In contrast, implementation of a densitydependent mortality rate enables reproduction of algae ciliate dynamics over a variety of environmental settings encompassed by the 14-year dataset spanning
\end{abstract}

O. Kerimoglu $\cdot$ D. Straile $\cdot$ F. Peeters

Limnological Institute, University of Konstanz, 78464

Constance, Germany

O. Kerimoglu $(\bowtie)$

INRA, UMR CARRTEL, 74203 Thonon les Bains, France

e mail: kerimoglu.o@gmail.com
21 years in a lake undergoing oligotrophication. Considering the numerous processes that can be responsible for the dampening of ciliate blooms, our findings suggest that employing a simple density-dependent mortality term offers a pragmatic solution for the challenge of including the microzooplankton, characterized by an overwhelming complexity of trophic interactions, in ecosystem models.

Keywords Ciliates · Phytoplankton - Copepods · Prey switching · Hydrodynamically driven biological model $\cdot$ Regression model

\section{Introduction}

Microzooplankton, particularly the ciliates, have been increasingly recognized as important components in aquatic food web, functioning not only as efficient consumers of primary production (Pace \& Orcutt, 1981; Beaver \& Crisman, 1989; Calbet \& Landry, 2004; Kerimoglu et al., 2013), but also as food source for metazoans (Berk et al., 1977; Stoecker \& Capuzzo, 1990; Weisse, 1991; Kleppel, 1993; Calbet \& Saiz, 2005). However, as a relatively "recent" focus of interest in comparison with, e.g., large crustaceans (Weisse, 2006) and possibly owing to the overwhelming diversity of trophic interactions they exhibit, the dynamics of microzooplankton communities are still not very well understood (Calbet, 2008). Although a majority of the ecosystem models in use still disregard 
this important component of the pelagic food web, microzooplankton compartments have been appearing in ecosystem models for almost two decades now (e.g., Baretta et al., 1995; Blackford et al., 2004; Bruce et al., 2006; Buitenhuis et al., 2010). However, mostly owing to the lack of monitoring datasets, estimations of microzooplankton concentrations have been either rarely tested against observation data, or the comparisons have been frequently rather poor, suggesting that even when these important components of aquatic food webs have been considered, estimation of energy and material fluxes might have been possibly inadequate. In this study, we take advantage of the longterm and high-resolution datasets on ciliates in Lake Constance, to discuss the plausibility of alternative model formulations for including ciliates in a simple pelagic food web of Lake Constance.

Ciliates respond quickly to the increases in their food sources because of their short generation times and form transient blooms (Strom \& Morello, 1998; Montagnes \& Lessard, 1999; Sherr \& Sherr, 2009), which is also reflected by a close coupling between the in situ algae and ciliate densities at the beginning of the growth season (Weisse et al., 1990; Tirok \& Gaedke, 2007). Regulation of ciliate blooms was attributed to a number of mechanisms. In a number of studies, food limitation has been considered to be the major regulator of protist populations (Beaver \& Crisman, 1989; Minter et al., 2011). However, predation by mesozooplankton, especially copepods (Wickham, 1995; Adrian \& Schneider-Olt, 1999; Jürgens et al., 1999; Calbet \& Saiz, 2005), interference competition by daphnids (Wickham \& Gilbert, 1993; Adrian \& Schneider-Olt, 1999) and intraguild predation, i.e., the feeding of large carnivorous ciliate species on smaller ones (Stoecker \& Evans, 1985; Dolan \& Coats, 1991) have been also shown to be important in regulating ciliate dynamics.

The aim of the current study is to evaluate the plausibility of alternative formulations to describe the losses of ciliates included as a state variable in a simple pelagic food-web model driven by a hydrodynamic model, on the basis of the performance of resulting models in reproducing the phytoplankton ciliate spring bloom dynamics as reflected by the datasets collected during the spring bloom period of 14 study years. Specifically, the formulations to describe the ciliate losses include (i) a classical constant specific mortality rate ("linear population mortality rate"); (ii) feeding by copepods, which is assumed to follow a type-III functional response, occurring through an active switch (Gentleman et al., 2003) from algal to ciliate diet with increasing ratio of ciliates in the environment; (iii) a constant specific mortality rate plus copepod feeding; and (iv) a densitydependent specific mortality rate (e.g., Steele \& Henderson, 1992), used here as an empirical tuning factor that may represent a range of loss processes (see "Discussion" section). We additionally develop a regression model that estimates ciliate abundances from algal abundances, performance of which is compared to that of the process-based models. In comparing these different modeling approaches, we aim (a) to contribute to the development of a parsimonious parameterization of ciliate dynamics to be potentially employed in ecosystem models which frequently ignore these important components of aquatic food webs, and (b) to improve our understanding of the regulation of ciliate dynamics during the spring period.

\section{Methods}

Study site

Upper Lake Constance is a large $\left(472 \mathrm{~km}^{2}\right)$, deep $\left(z_{\max }=252 \mathrm{~m}\right)$, and typically warm-monomictic lake located at the northern fringe of the western European Alps $\left(47^{\circ} 50^{\prime} \mathrm{N}, 9^{\circ} 20^{\prime} \mathrm{E}\right)$. Most of our data stem from 147-m-deep Lake Überlingen, a sub-basin of Lake Constance that is very well connected to the main basin, with 80-m water depth at the sill connecting the basins. In Lake Constance, which is a phosphorus limited system (Häse et al., 1998), the SRP concentrations during winter mixing (February March), decreased approximately 10 -fold, from an average $48.4\left[\mu \mathrm{g} \mathrm{l}^{-1}\right]$ in 19871988 to an average $4.8\left[\mu \mathrm{g} \mathrm{l}^{-1}\right.$ ] in 20062007.

In Lake Constance, ciliate blooms were shown to be terminated before the daphnids emerge in 10 out of 12 years between 1987 and 1998 (Tirok \& Gaedke, 2006).Thus, in this article, we focus on the regulation of ciliates in spring, during which Daphnia are not present yet. The threshold-integrated Daphnia biomass over the water column, after which they were considered to have significant impact on algae ciliate dynamics was assumed to be $1,000\left[\mathrm{mgC} \mathrm{m}^{-2}\right]$ (Tirok 
\& Gaedke, 2006). The day of year Daphnia abundance exceeds this threshold will be referred to as the "emergence of Daphnia" from this point forward.

\section{Sampling}

Plankton and Chlorophyll $a$ (from hereon, $\operatorname{chl} a$ ) were sampled weekly during the growth season and less regularly during winter at the deepest spot $(147 \mathrm{~m})$ of the sub-basin Überlingersee. chl $a$ was determined spectrometrically after hot ethanol extraction (Häse et al., 1998), at 20 depths within the $060 \mathrm{~m}$. Algae biomass in carbon units was calculated assuming a constant C: chl $a$ ratio of 20. Crustacean zooplankton was collected by hauls from $140 \mathrm{~m}$ with a $140 \mu \mathrm{m}$ Clarke-Bumpus Sampler and its biomass values were calculated from length weight relationships established for Lake Constance (Geller \& Müller, 1985; Wölfl, 1991). Ciliates were counted in water samples collected from 0 8-m and from 8 20-m depths during 1987 1998, and in samples collected from 0 20-m depth in 2006 and 2007, and were converted to biomasses in carbon units based on empirical relationships (Müller, 1989). Soluble reactive phosphate concentrations are available from monthly measurements in the main basin of Lake Constance (Rossknecht, 1998).

The process-based models

The model employed in this study is an extended version of the one dimensional phytoplankton model driven by lake hydrodynamics described by (Peeters et al., 2007a, b) that was demonstrated to adequately reproduce the inter-annual variability in the timing of algal bloom between 1987 and 1995 in Lake Constance. The vertically resolved model calculates the change of Algae concentration (A) per unit time according to:

$$
\begin{aligned}
\frac{\partial A}{\partial t}= & P_{\mathrm{A}}\left(1-R_{\mathrm{A}}\right) A-D_{\mathrm{A}}-\sum_{i} I_{i, \mathrm{~A}} Z_{i}+S_{\mathrm{A}} \\
& +\frac{\partial}{\partial z}\left(K_{\mathrm{z}} \frac{\partial A}{\partial z}\right)-v_{\mathrm{A}} \frac{\partial A}{\partial z}
\end{aligned}
$$

where $P_{\mathrm{A}}$ is the specific algal growth rate, $R_{\mathrm{A}}$ is the fraction of production lost to respiration (Geider \& Osborne, 1989), $D_{\mathrm{A}}$ is the basal mortality rate, $Z_{i}$ is the biomass concentration of the zooplankton group $i$ and
$I_{i, \mathrm{~A}}$ is their biomass specific rate of ingestion of algae, $S_{\mathrm{A}}$ is the seeding rate, $K_{\mathrm{z}}$ is the turbulent diffusion coefficient calculated by the physical model, $v_{\mathrm{A}}$ is the phytoplankton sinking rate and $z$ is the depth. Parameters of the algae model are the same as in Peeters et al. $(2007 \mathrm{a}, \mathrm{b})$ for the processes with identical representations (see below), and were determined from extensive literature on Lake Constance (Table 1). Algae growth was considered to be limited by nutrients (in this case, phosphate) as a Monod function and light as a hyperbolic tangent function (Jassby \& Platt, 1976), following the Liebig's law of minimum:

$P_{\mathrm{A}}(z)=\theta{ }^{1} p_{\mathrm{sp}}^{\max } \min \left[\tanh \left(\frac{\alpha L(z)}{p_{\mathrm{sp}}^{\max }}\right), \frac{N(z)}{N(z)+K_{\mathrm{N}}}\right]$

where $p_{\mathrm{sp}}^{\max }$ is the maximum specific growth rate per chlorophyll content, $\theta$ is the carbon to chlorophyll ratio, $L$ is the light intensity [W m$~^{-2}$ ], $\alpha$ is the initial slope of light-growth curve, $N(z)$ is the nutrient resource, i.e., soluble reactive phosphorus (SRP) concentration read from observation data and $K_{\mathrm{N}}$ is the half saturation constant for phosphorus uptake. SRP concentrations were originally measured at $0-, 1-$, 2.5-, 5-, 7.5-, 10-, 15-, 20-, 30-, 50-, 100-, 150-, 200-, 230- and 250-m depth levels, but were then linearly interpolated to the model grid. Light intensity throughout the water column is calculated at each time step according to the Lambert Beer law while light extinction attenuation is calculated according to Tilzer (1988):

$L(z)=L_{0} e^{\int^{2}}\left(\left(k_{\mathrm{w}}+k_{\mathrm{chl}} A\left(z^{\prime}\right) \theta^{1}\right) d z^{\prime}\right.$

where, $k_{\mathrm{w}}$ and $k_{\mathrm{chl}}$ are, respectively, the background and chlorophyll specific extinction coefficients.

Herbivores other than ciliates; i.e., Daphnia, cyclopoid copepods, Eudiaptomus gracilis, and Bosmina spp., were not modeled dynamically but their abundances were read from the observation data. This procedure substantially reduces the number of parameters, hence the model complexity, but requires availability of consistent and temporally high-resolution datasets. With the exception of the models investigating the role of food-switching in copepods (see below), ingestion of all herbivores, including ciliates, was described by a functional response type II: 
Table 1 Model parameters

\begin{tabular}{|c|c|c|c|c|}
\hline Symbol & Description & Unit & Value & Src. \\
\hline \multicolumn{5}{|c|}{ Kinetic parameters (reference temperature, $T^{\prime} \quad 10^{\circ} \mathrm{C}$ ) } \\
\hline$p_{s p}^{\max }$ & Algae max. specific growth rate & $\mathrm{mg}_{\mathrm{C}} \mathrm{mg}_{\mathrm{chl}}^{-1} \mathrm{~d}^{-1}$ & 67.2 & a \\
\hline$D_{\mathrm{A}}$ & Algae basal mortality rate & $\mathrm{d}^{-1}$ & 0.02 & $\mathrm{~b}$ \\
\hline$q_{\mathrm{cil}}$ & Ciliate quadratic mortality constant & $\mathrm{m}^{3} \mathrm{mgC}^{-1} \mathrm{~d}^{-1}$ & 0.0025 & $\mathrm{~m}$ \\
\hline$d_{\mathrm{cil}}$ & Ciliate linear mortality constant & $\mathrm{d}^{-1}$ & $0.08,0.04$ & $\mathrm{n}$ \\
\hline$I_{\max , \mathrm{Cil}}$ & Ciliates max. ingestion rate & $d^{-1}$ & 2.8 & $\mathrm{c}$ \\
\hline$I_{\text {max,daph }}$ & Daphnia max. ingestion rate & $d^{-1}$ & 0.8 & $\mathrm{~d}$ \\
\hline$I_{\max , \text { bos }}$ & Bosmina max. ingestion rate & $\mathrm{d}^{-1}$ & 0.5 & $\mathrm{~d}$ \\
\hline$I_{\max , \text { cop }}$ & Copepod max. ingestion rate & $d^{-1}$ & 0.5 & $\mathrm{e}$ \\
\hline \multicolumn{5}{|c|}{ Other biological parameters } \\
\hline$v_{\mathrm{A}}$ & Algae sinking rate & $\mathrm{m} \mathrm{d}^{-1}$ & 0.2 & $\mathrm{f}$ \\
\hline$k_{\mathrm{w}}$ & Background light absorption coeff. & $\mathrm{m}^{-1}$ & 0.27 & $\mathrm{~g}$ \\
\hline$k_{\mathrm{chl}}$ & chl specific light absorption coefff. & $\mathrm{m}^{2} \mathrm{mg}_{\mathrm{chl}}^{-1}$ & 0.021 & $\mathrm{~g}$ \\
\hline$\alpha$ & Slope of the light $(\mathrm{L})$ growth $(\mathrm{P})$ curve & $\mathrm{gC}_{\text {alg }} \mathrm{g}_{\mathrm{chl}}^{-1} \mathrm{~m}^{2} \mathrm{~W}^{-1} \mathrm{~d}^{-1}$ & 0.82 & $\mathrm{~h}$ \\
\hline$\Theta$ & C: $\operatorname{chl} a$ & $\mathrm{C} \operatorname{chl} a^{-1}$ & 20 & $\mathrm{i}$ \\
\hline$K_{\text {alg }}$ & Half sat. const. for phosphate uptake & $\mu \mathrm{gP} 1^{-1}$ & 8 & $\mathrm{k}$ \\
\hline$R_{\mathrm{A}}$ & Respired fraction of algal production & $\mathrm{C}_{\mathrm{alg}} \mathrm{C}_{\mathrm{alg}}^{-1}$ & 0.2 & $\mathrm{~b}$ \\
\hline$S_{\mathrm{A}}$ & Phytoplankton seeding rate & $\mu g C 1^{-1} \mathrm{~d}^{-1}$ & 0.2 & $\mathrm{k}$ \\
\hline$S_{\mathrm{Cil}}$ & Ciliate seeding rate & $\mu \mathrm{gC} 1^{-1} \mathrm{~d}^{-1}$ & 0.04 & 1 \\
\hline$K_{\text {cil }}$ & Half sat. const. for grazing by ciliates & $\operatorname{mgC} 1^{-1}$ & 0.75 & $\mathrm{c}$ \\
\hline$K_{\text {daph }}$ & Half sat. const. for grazing by Daphnia & $\operatorname{mgC~} 1^{-1}$ & 0.5 & $\mathrm{~d}$ \\
\hline$K_{\text {bos }}$ & Half sat. const. for grazing by Bosmina & $\operatorname{mgC~} 1^{-1}$ & 0.13 & $\mathrm{~d}$ \\
\hline$K_{\text {cop }}$ & Half sat. const. for grazing by copepods & $\operatorname{mgC~} 1^{-1}$ & 0.5 & $\mathrm{e}$ \\
\hline$\gamma_{\text {Cil }}$ & Ciliate gross growth efficiency & $\mathrm{C}_{\mathrm{cil}} \mathrm{C}_{\mathrm{alg}}^{-1}$ & 0.3 & $\mathrm{j}$ \\
\hline$p_{\text {cop,Cil }}$ & Ciliate preference by copepods & & 0.9 & o \\
\hline$p_{\text {cop,A }}$ & Algae preference by copepods & & 0.1 & o \\
\hline$Q_{10} a$ & Temp. dependence of autotr. processes & & 2.3 & a \\
\hline$Q_{10} z$ & Temp. dependence of heter. processes & & 2 & $\mathrm{p}$ \\
\hline
\end{tabular}

Src. (sources): (a) Häse et al. (1998), (b) Geider \& Osborne (1989), (c) Based on mean values by Weisse et al. (2001) and consideration of lower values used by Buitenhuis et al. (2010) and Bruce et al. (2006), (d) Mean values of the corresponding groups compiled in Hansen et al. (1997), (e) Santer \& van den Bosch (1994), (f) Sommer (1984), (g) Tilzer (1988), (h) Häse (1996), (i) estimated by inspecting the yearly courses of C:Chl $a$ ratios for Lake Constance. (j) Straile (1997), (k) adjusted for a phytoplankton only model and applied globally, (1) scaled to $S_{\mathrm{A}}$ according to the January April average ciliate/algae ratio of 0.2 during 1987 1998, 2006, $2007 \mathrm{~m}$ ) adjusted (for MQ only), (n) adjusted (values for ML and MCL, respectively), (o) prescribed (for MC and MCL), (p) as a general rule

$I_{i, \mathrm{~A}}=I_{\max , \mathrm{i}} \frac{A(z)}{K_{i}+A(z)}$

where $I_{\max , i}$ and $K_{i}$ are, respectively, the maximum ingestion rate and half-saturation constant of the species $i$. Except for the ciliates, the data files provided zooplankton biomasses as integrated measures over the entire water column. As in Peeters et al. (2007b), we assumed that in spring, zooplankton is concentrated in the upper $20 \mathrm{~m}$ of the water column and that their vertical distribution is proportional to that of their food:

$Z_{i}(z)=\frac{F(z)}{\int_{0}^{20} F(z) d z} \int_{0}^{20} Z_{i}(z) d z$

where the integral term in the nominator corresponds to the measured total abundance of zooplankton 
species $i$ per unit area. Since herbivores only feed on algae except in the copepod feeding model (see below), $F(z)$, the food concentration at depth $z$, corresponds to $A(z)$, the algae concentration at depth $z$.

Finally, the seeding term, $S_{\mathrm{A}}$, refers to a small and constant amount of phytoplankton input, adjusted to be $0.2\left[\mu \mathrm{gC}^{-1} \mathrm{~d}^{-1}\right]$ throughout the water column. It practically improves the representation of algae over the winter by keeping a sufficient density of algae within the photic zone to enable a rapid response to the establishment of stratification as observed in the field. Such seeding terms has been previously used in similar models mainly to set the initial values of phytoplankton and zooplankton at the onset of vernal blooms (Fennel \& Neumann, 1996) or to incorporate the stabilizing mechanism induced by spatial heterogeneity commonly observed in plankton communities (Scheffer \& De Boer, 1995). For a deep lake, such an inflow to the pelagic can occur because of heterogeneities caused by the differences in light limitation experienced by the littoral and pelagic communities, and wind-induced mixing as well as augmented convective flow due to cooling and heating differentials (MacIntyre \& Melack, 1995).

The model simulates ciliate concentrations dynamically. The net rate of change of ciliate concentration $\left(Z_{\mathrm{Cil}}\right)$ is described by the net gains as the product of ingested algae biomass with an efficiency factor accounting for the excretion and basal respiration, the losses as a mortality term and an explicit predation term by the other zooplankton, and finally a diffusive transport term. It was assumed that sinking losses of ciliates are negligible, so that there is no advective transport.

$$
\begin{aligned}
\frac{\partial Z_{\mathrm{Cil}}}{\partial t}= & \gamma_{\mathrm{Cil}} I_{\mathrm{Cil}} Z_{\mathrm{Cil}}-D_{\mathrm{Cil}} Z_{\mathrm{Cil}}-\sum_{i} I_{i, \mathrm{Cil}} Z_{i}+S_{\mathrm{Cil}} \\
& +\frac{\partial}{\partial z}\left(K_{\mathrm{z}} \frac{\partial Z_{\mathrm{Cil}}}{\partial z}\right)
\end{aligned}
$$

where, $\gamma_{\mathrm{Cil}}$ is the gross growth efficiency, $D_{\mathrm{Cil}}$ is the specific mortality rate of ciliates, $I_{\mathrm{Cil}, \mathrm{A}}$ is the ingestion rate of algae by ciliates, $I_{i, \mathrm{Cil}}$ is the ingestion rate of ciliates by zooplankton species $i$, and $S_{\mathrm{Cil}}$ is a seeding term analogous to that in the phytoplankton model (Eq. 1). Seeding of ciliates, as in the case of algae, basically improves their representation over the winter season by keeping their biomasses from decreasing to unrealistically low values over the winter months. In order to be consistent with the seeding rate adjusted for phytoplankton, $S_{\mathrm{A}}$, the seeding rate of ciliates was set to $S_{\mathrm{Cil}}=0.04\left[\mu \mathrm{gC} 1^{-1} \mathrm{~d}^{-1}\right]$ throughout the water column, upon examination of algae chl $a$ ratios within the first 120 days of the study period.

All kinetic model parameters (Table 1) were made dependent on the ambient temperature by the $\mathrm{Q}_{10}$ law (not shown in the above equations to facilitate readability):

$\left.r(T)=r\left(T^{\prime}\right) Q_{10}^{\left(T / T^{\prime}\right.} 1\right)$

where, $r(T)$ is the value of the parameter at ambient temperature $(T)$, and $r\left(T^{\prime}\right)$ is the value of the parameter at the reference temperature, $T$, which was taken as $10^{\circ} \mathrm{C}$.

\section{Variations to the process-based models}

Three model variants were considered in this study reflecting different food-web structures (Fig. 1). The models differed only in the formulation of the ciliate compartment, while the rest of the model equations were kept identical except for grazing of algae by copepods, $I_{\mathrm{Cil}, \mathrm{A}}$ (otherwise given by Eq. 4 ) in the model structure assuming copepod selective feeding on algae and ciliates (see below).

Model linear mortality (ML) It is assumed that specific mortality rate is density independent $\left(D_{\mathrm{Cil}}=d_{\mathrm{Cil}}\right)$, resulting a linear population loss rate $\left(d_{\mathrm{Cil}} Z_{\mathrm{Cil}}\right)$. Losses to other zooplankton were not considered explicitly. A linear population mortality

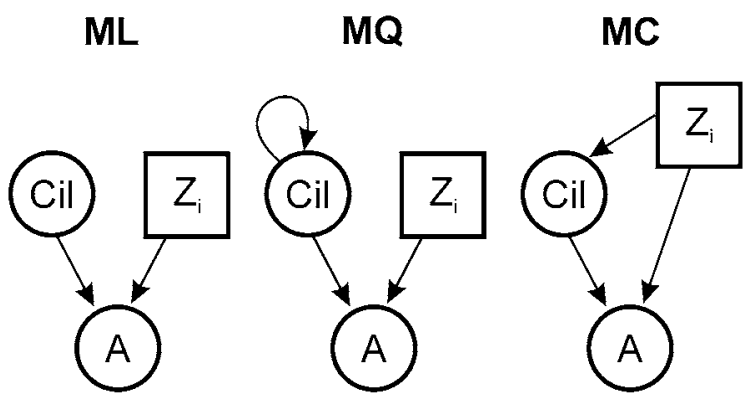

Fig. 1 Schematic representation of implemented feeding inter actions in the process based models. $\mathrm{A}, \mathrm{Cil}$, and $Z_{i}$ respectively stand for the algae, ciliates, and other zooplankton groups. Algae and Ciliates were dynamic variables (indicated by circles) and the other zooplankton groups were static variables (rectangle) in the models 
rate as in this model has been in frequent usage to describe predator mortality since the early LotkaVolterra models (e.g., Fasham et al., 1990).

Model copepod feeding (MC) It is assumed that ciliate mortality is only due to predation by cyclopoid copepods and Eudiaptomus and $D_{\mathrm{Cil}}=0$. Copepods were shown to "actively" switch between algae and ciliates (Landry, 1981; Kiorboe et al., 1996; Gismervik \& Andersen, 1997; Saage et al., 2009); therefore, we adopted switching formulations that result in a disproportionate increase in the ingestion of ciliates with their availability (Murdoch, 1969). If a type-2 functional response is assumed, following the notation from Eq. 4, ingestion of food item $j$ (ciliates and algae), by consumer $i$ (copepods) can be calculated by

$I_{i, j}=I_{i, j} \frac{p_{i, j}^{\prime} F_{j}}{K_{i}+\sum_{j} p_{i, j}^{\prime} F_{j}}$

where $p_{i, j}^{\prime}$ describes effective preference, $F_{j}$ is the density of food item $j$ and $K_{i}$ is the ingestion half saturation constant of the consumer $i$. Active switching can be implemented by making effective preferences functions of food densities. An example of this is the "ratio-based switching" (Fasham et al., 1990), in which, the effective preference, $p_{i, j}^{\prime}$ is calculated as the relative abundance of a given food item weighted by an affinity parameter (of consumer $i$ to food $j$ ), $p_{i, j}$ in the total weighted food pool.

$p_{i, j}^{\prime}=\frac{p_{i, j} F_{j}}{\sum_{j} p_{i, j} F_{j}}$

In order to make a case for strong selection for ciliates as the preferred food, we use $p_{i, \mathrm{Cil}}=0.9$ and $p_{i, \mathrm{Cil}}=0.1$ for both $i$ : Eudiaptomus and cyclopoid copepods.

In the MC model, vertical distribution of copepods in the upper $20 \mathrm{~m}$ was based on the abundance of two resources instead of one; therefore Eq. 5 was also modified. This is implemented simply by assuming that the distribution is based on the "perceived" total food pool, which consists of the sum of algae and ciliate densities weighted by effective preferences:
$F(z)=\sum_{j} p_{i, j}^{\prime} F_{j}$

As the predation rate of copepods on ciliates increases with increasing ciliate abundances, the loss term functionally acts like a density-dependent mortality rate, as in the case of MQ.

Model copepod feeding and linear mortality combined $(M C L)$ The direct interference by copepods, as described above for the MC, and a linear mortality rate of ciliates as in ML are combined in this model structure. It turns out (see below) especially in the eutrophic years that the regulation of ciliates requires density-dependent regulation and that the mortality caused only by copepods in the MC does not fulfill this requirement, and therefore, the aim of this model is to verify whether a background nondensity-dependent loss rate in addition to the feeding by copepods can provide a better representation of the algae ciliate dynamics.

Model quadratic mortality (MQ) It is assumed that the specific mortality rate is density dependent $\left(D_{\mathrm{Cil}}=q_{\mathrm{Cil}} Z_{\mathrm{Cil}}\right)$, resulting in a quadratic population mortality rate $\left(q_{\mathrm{Cil}} Z_{\mathrm{Cil}}^{2}\right)$. Feeding by other zooplankton was not considered explicitly. and thus $I_{i, \mathrm{Cil}}=0$. The concept of quadratic population mortality has not only been an intensively investigated theoretical concept, e.g., with regard to its effects on the stability of predator prey dynamics (Steele \& Henderson, 1992; Alewell \& Manderscheid, 1998; Edwards \& Yool, 2000) but has also been employed in ecosystem models designed to simulate the field conditions (e.g., Fasham, 1995). Use of a density-dependent specific mortality rate in models has often been motivated by the lack of explicitly described upper trophic links (e.g., Steele \& Henderson, 1992), or the presence of omnivorous forms in the modeled group (Taylor \& Joint, 1990). Considering the extreme diversity of trophic interactions exhibited by the ciliates as will be summarized in the "Discussion" section, we perceive the quadratic mortality rate as an empirical tuning parameter that might emulate an ambiguous set of processes, rather than coining a particular one of those. 


\section{Operation of the process-based models}

Vertical profiles of temperature and turbulent diffusivities that were used in the biological model were calculated by a $1 \mathrm{D}$ model that is based on $\mathrm{k}-\varepsilon$ closure scheme, SIMSTRAT, details about which can be found in Goudsmit et al. (2002) and Peeters et al. (2002). SIMSTRAT was calibrated by minimizing the difference between simulated and observed temperature profiles for 1979 1994, operated with 10-min time steps, and forced with hourly measurements of wind speed (converted to lake-level speeds by multiplication with a factor of 1.3 upon observed differences), wind direction, air temperature, solar radiation, humidity, and cloud cover, taken from the DWD (Deutscher Wetterdienst, German weather service) station in Konstanz, located 47 meters above lake surface level. Light extinction coefficients were calculated from the observed chl $a$ concentrations according to Eq. 3 and were provided to the physical model as a one-time biological feedback. The processbased models had a vertical resolution of $1 \mathrm{~m}$ and were initiated at the first day of each year with linearly interpolated chl $a$ concentrations in time and space, and linearly interpolated top-20-m ciliate concentrations in time, with vertical distributions calculated according to Eq. 5. The set of ordinary differential equations was solved using the implicit MATLAB (C) algorithm ODE15s with dynamic time stepping. Further details regarding the model operation can be found in Peeters et al. (2007b). The half-saturation constant for phosphate uptake of the algae $\left(K_{\mathrm{P}}\right)$ was manually adjusted for a simplified model in which ciliate was not a state variable but a static variable read from data files as in the case of the other zooplankton units. Extension of the algae model with a dynamic ciliate compartment resulted in an additional free parameter for mortality rate constant in case of $\mathrm{MQ}$, ML, and MCL. Adjustment of these parameters is explained in the Results section.

\section{Regression Models (MR)}

As a strong test for the performance of the processbased simulation models we compared these models with the performance of regression models predicting ciliate biomass from chlorophyll concentration measured at the same sampling day (MR1). In order to account for possible seasonal changes in algae ciliate relationships, we additionally consider regression models in which we allow for monthly differing intercepts (MR2) and monthly differing slopes and intercepts (MR3). For regression models, both ciliate biomass and chl a concentrations were log transformed to ensure normality and variance heterogeneity. Regression analysis was performed with the software package SAS (SAS Institute Inc., 2004).

\section{Skill metrics}

For the estimation of mortality rate parameters and for the evaluation of model performances, a set of model performance metrics were evaluated. Besides the widely used coefficient of determination (explained variance), calculated here as the square of the correlation coefficient between the modeled and observed values (Weglarczyk, 1998) on a log space, the normalized mean absolute error (NMAE; Alewell \& Manderscheid, 1998) and the root mean square error (RMSE, Janssen \& Heuberger, 1995) are given, respectively, by

$$
\begin{aligned}
\mathrm{NMAE} & =\frac{\sum_{i=1}^{n}\left|S_{i}-O_{i}\right|}{n \bar{O}} \\
\mathrm{RMSE} & =\sqrt{\frac{\sum_{i=1}^{n}\left(S_{i}-O_{i}\right)^{2}}{n}}
\end{aligned}
$$

where $n$ is the number of observations, $O_{i}$ is the $i$ th observation, $S_{i}$ is the simulated value at the time of $i$ th observation, and $\bar{O}$ is the mean of all $n$ observations. Note that, observations and simulated values refer to the $020-\mathrm{m}$ average concentrations. As all of these metrics suffer from potential phase errors in time, we also evaluated the mean percentage error for the spring peaks (MPEP), which summarizes the information about the under/over estimation of peaks and the mean absolute percentage error for the spring peaks (MAPEP), which provides the information about the overall deviation from the peak magnitudes:

$$
\begin{gathered}
\mathrm{MPEP}=\frac{\sum_{y}^{N}\left(\mathrm{PS}_{y}-\mathrm{PO}_{y}\right) / \mathrm{PO}_{y}}{N} \\
\text { MAPEP }=\frac{\sum_{y}^{N}\left|\mathrm{PS}_{y}-\mathrm{PO}_{y}\right| / \mathrm{PO}_{y}}{N}
\end{gathered}
$$

where, $N$ is the number of years, $\mathrm{PO}_{y}$ and $\mathrm{PS}_{y}$ are maximum observed and simulated values, respectively, in year $y$. As a complementary measure to $R^{2}$, 
NMAE, and RMSE, the MPEP and MAPEP provide the additional values of reflecting the success of models for reproducing the bloom events which have ecological significance (Sommer et al., 1986; Smayda, 1997).

\section{Analysis of residuals}

To evaluate a potential bias of the various model formulations with regard to environmental parameters, we test whether average spring period values of SRP concentrations, copepod biomass, daphnid biomass, water temperature, and turbulent diffusivity as calculated by the hydrodynamical model are related to modeled residuals of peak ciliate biomass. We use a backward selection method to remove nonsignificant independent variables until all remaining variables are significant at $P<0.05$. Analysis of residuals was performed using the software package SAS (SAS Institute Inc., 2004).

\section{Results}

The hydrodynamical model provided an adequate description of the physical settings in terms of spring water temperatures and stratification dynamics, as suggested by the good match between the simulated and available measured temperatures within the upper $20 \mathrm{~m}$ for the entire simulation period (Fig. 2).

The mortality rate constants for MQ, ML, and MCL were adjusted based on a subjective optimization of multi-objective criteria captured by the skill metrics presented above, namely the $R^{2}$, NMAE, RMSE, and MPEP as summarized for two of these metrics in Fig. 3. As increasing ciliate mortality rate causes the estimated ciliates to shrink in magnitude, while phytoplankton, to grow, thus has opposite effects on the abundance of ciliates and algae, especially the measure of bias, MPEP, but also generally the deviance measures such as NMAE calculated for algae and ciliates display opposing gradients over the range of tested mortality rate coefficients. Therefore, although it would have been possible to improve the ciliate-based skill scores with higher mortality rate coefficients, it would be in the expense of algae-based scores (Fig. 3).

During the study period, ciliate biomass was strongly associated with chl $a$ concentrations, and $\log 10(\mathrm{chl} a)$ predicts $59 \%$ of the variability of $\log$ transformed cililate biomass $(P<0.0001$, MR1 in Table 2). Allowing for monthly specific intercepts of
Fig. 2 Temperatures measured by the thermistor chains (thin lines) and simulated by SIMSTRAT (thick lines) at 4 (red) and 10 (green), and $20 \mathrm{~m}$ (blue) depths, averaged to 1 day intervals

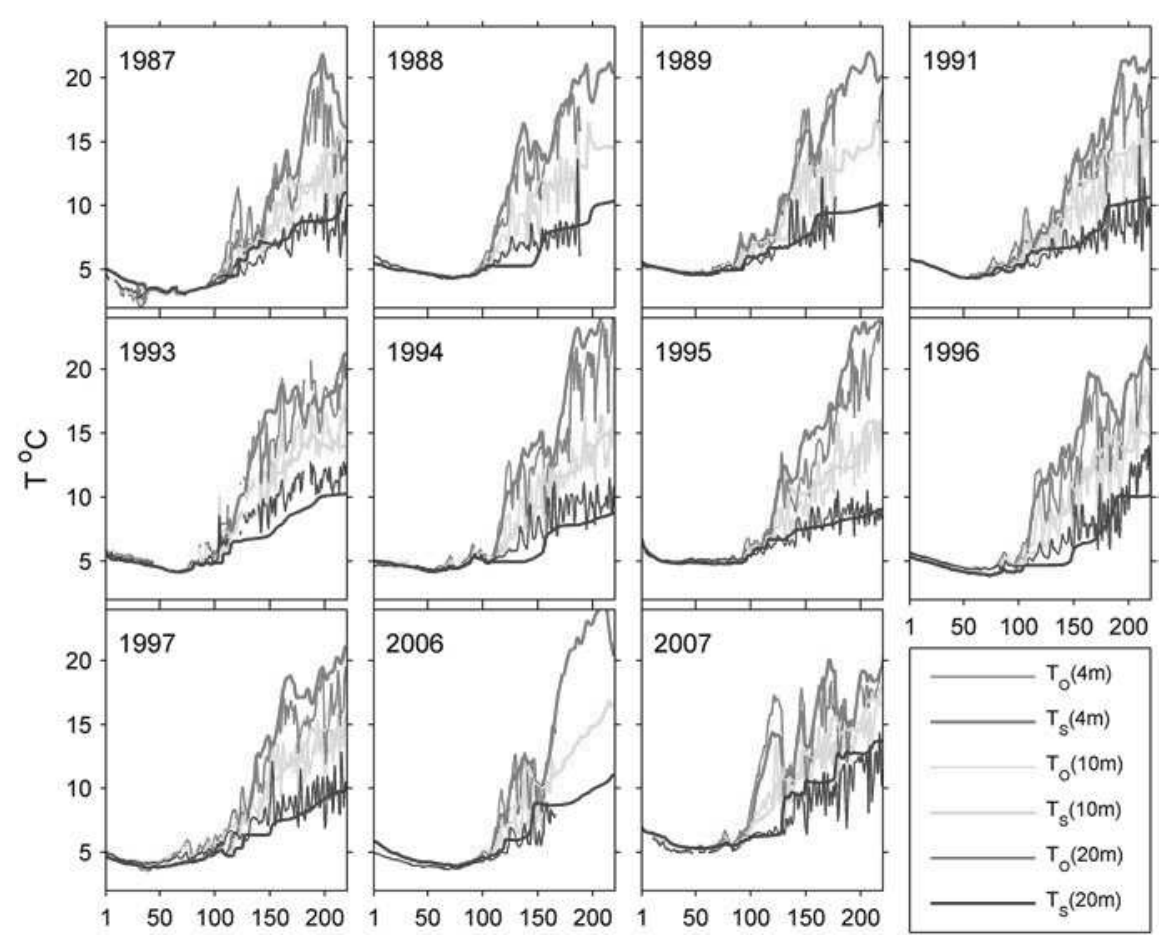


the chl $a$ ciliate biomass relationship increases model $R^{2}$ to $0.69(P<0.0001$, MR2 in Table 2$)$. While the data support the assumption of monthly variation in the intercept of this relationship, monthly specific slopes were not supported (MR3) and did hardly increase model $R^{2}$ further. Therefore, for comparing with the process-based models, we only consider the model MR2.

Time series of the measured and simulated average concentration of ciliates and algae in the top $20 \mathrm{~m}$ are shown in Figs. 4 and 5, respectively. While the ML, MCL and MC frequently overestimated the ciliate blooms that consequently lead the phytoplankton concentrations to fall below the observed levels, MQ simulations seemed to be in agreement with measurements in most of the years. The MR2 seemed to perform better than the process-based models in capturing the variability before the onset of blooms, however, it systematically underestimated the peak

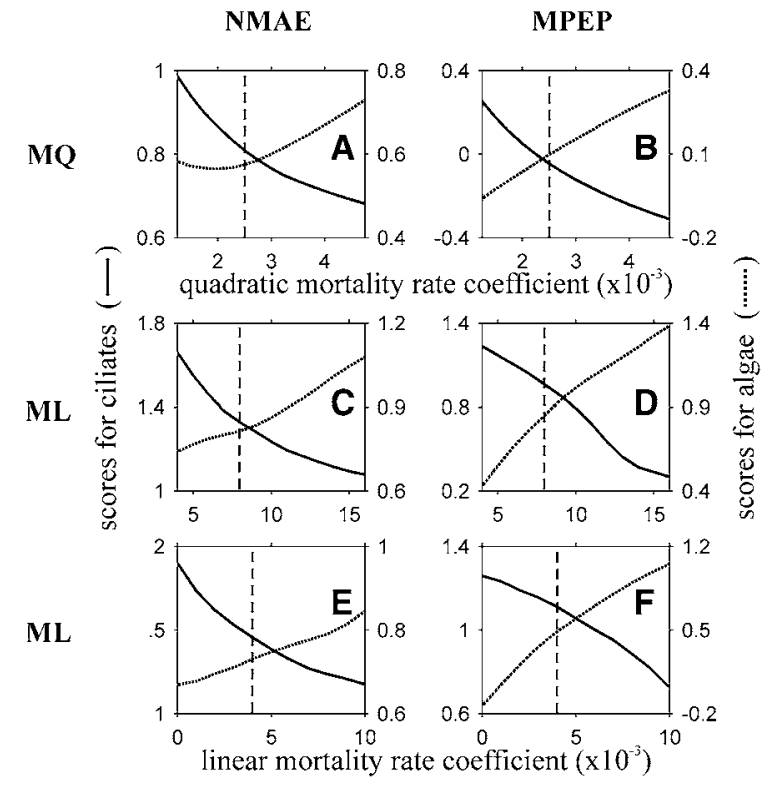

Fig. 3 Summary of the quantitative guidance for the adjust ment of mortality rate coefficients for the quadratic mortality model (A B), linear mortality model (C D) and combined linear mortality and copepod feeding model $(\mathbf{E} \mathbf{F})$, for which, the variation of normalized mean absolute error (NMAE; panels $\mathbf{A}, \mathbf{C}, \mathbf{E}$ ) and mean percent error for the peaks (MPEP; panels $\mathbf{B}$, D, F) for ciliates (solid lines) and algae (dotted lines) are shown. Data for the winter and bloom period, i.e., day 1 until the emergence of Daphnia in each of the years 19871998 , 20062007 were employed ( $n \quad 253$ for algae, $n \quad 220$ for ciliates). Final chosen values are indicated with dashed vertical lines magnitudes in all years. Note that, as the processbased models do not account for the direct and indirect effects of Daphnia on ciliates (e.g., additional loss terms and higher algal abundances due to enhanced nutrient recycling), simulation results for the time periods after the emergence of Daphnia marked for each year in Figs. 4 and 5 are not considered in this study.

Skill scores for the two dynamically simulated state variables, ciliates, and algae, obtained for all model structures considered in this study for the period between day 1 and until the emergence of Daphnia in each of the years during 19871998 and 20062007 ( $n=253$ for algae, $n=200$ ) are presented in Table 3 . Among the process-based models, MQ explains more of the variance and attained lower NMAE and RMSE for both ciliates and algae than the other process-based models (Table 3 ). With regard to the ciliate peaks, MQ attained an almost perfect MPEP score of -0.05 , although the slightly higher MAPEP indicates that there was some degree of compensation between the over- and under-estimated peaks. The ML, MC, and MCL overestimated the ciliates in all years except 2007 and by $100 \%$ on average as reflected by the MPEP. For the estimation of algal peaks, only the MC attained a slightly lower MAPEP for the algae than the MQ, but this was at the expense of very large MPEP and MAPEP for the ciliates (Table 3).

The performance of MQ for simulating ciliates was comparable to that of the MR2, being inferior with respect to the explained variance and NMAE and better with respect to RMSE, MPEP, and MAPEP. The success of MR2 with regard to $R^{2}$ and NMAE was primarily related with the time periods further away

Table 2 Results of regression models predicting log trans formed ciliate biomass from log transformed chl $a$ concentra tions. While MR consists of a single intercept and slope for the entire dataset, MR2 allows intercepts to be month specific and MR3 allows both the intercepts and slopes to be month specific

\begin{tabular}{lllll}
\hline Model & $\begin{array}{l}\text { Independent } \\
\text { variables }\end{array}$ & $F$ & $P$ & $R^{2}$ \\
\hline MR1 & $\log 10(\operatorname{chl} a)$ & $F_{1,199}=283$ & $<0.0001$ & 0.59 \\
MR2 & $\log 10(\operatorname{chl} a)$ & $F_{1,199}=56.2$ & $<0.0001$ & 0.69 \\
& Month & $F_{5,199}=13.5$ & $<0.0001$ & \\
MR3 & $\log 10(\operatorname{chl} a)$ & $F_{1,199}=41.6$ & $<0.0001$ & 0.70 \\
& Month & $F_{5,199}=13.2$ & $<0.0001$ & \\
& $\log 10(\operatorname{chl} a) *$ month & $F_{5,199}=1.3$ & ns & \\
\hline
\end{tabular}




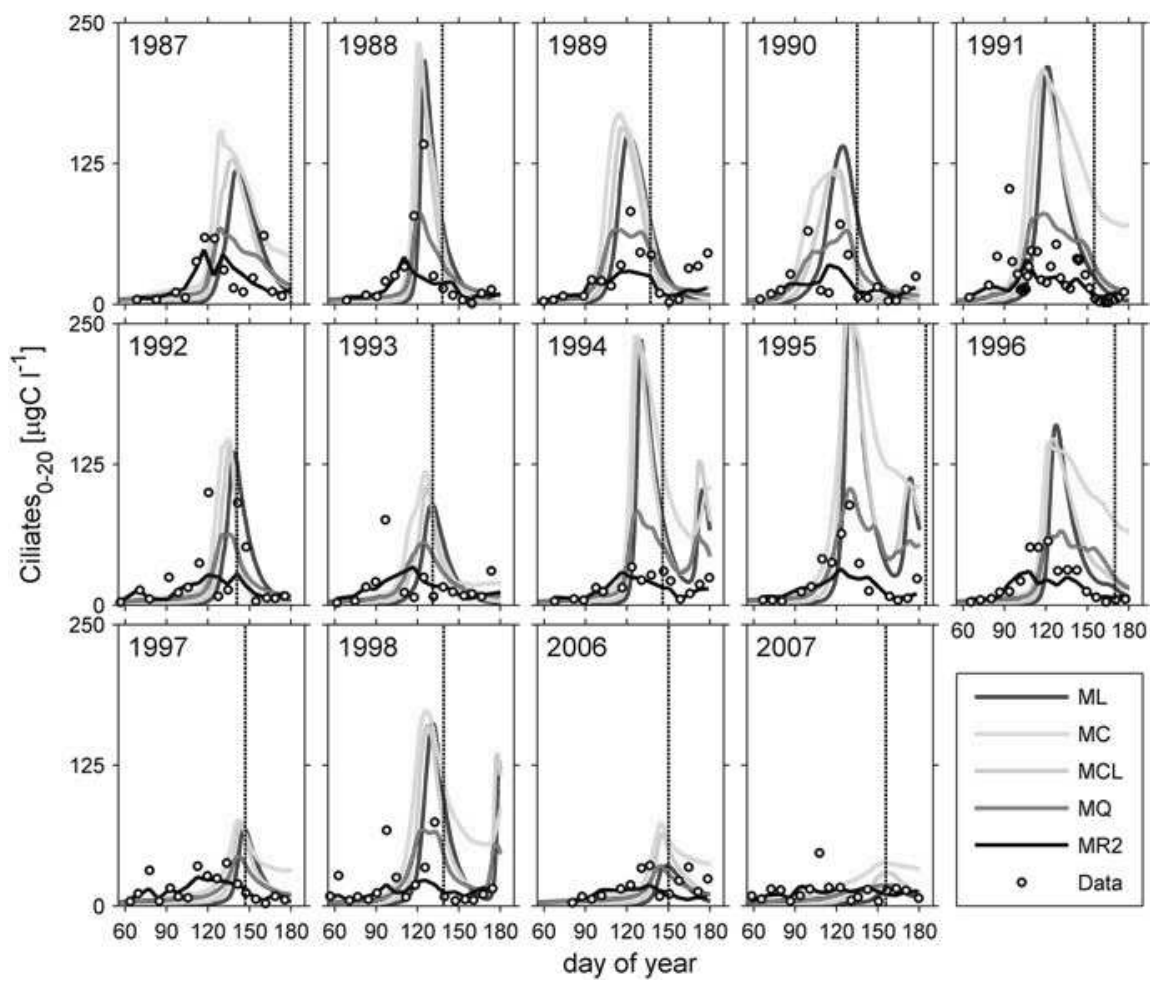

Fig. 4 Time series plots of modeled (lines) and observed (circles) ciliate and algae concentrations for the entire 14 years ciliate data is available. Lines with different colors indicate different modeling schemes: ML (blue): ciliate losses as a linear mortality term $\left(d_{\text {cil }} \quad 0.08 \mathrm{~d}^{-1}\right)$; MC (light green): ciliate losses as copepod feeding; MCL (cyan): ciliate losses as a linear

from the peak event, i.e., during the winter-early spring periods, in which ciliates occasionally accumulated in the surface layers (Fig. 4) and the processbased models invariably failed to capture these events. On the other hand, the systematic underestimation of ciliate peaks by the MR2 as opposed to the fairly good performance of MQ for estimating the peaks were not only captured by the MPEP and MAPEP but also reflected to the RMSE scores, as this metric is more sensitive to larger values.

No significant model emerges from backward model selection for the MQ residuals regarding maximum ciliate biomass, while the residuals of all other models showed a significant bias, i.e., were significantly related to average spring copepod biomasses, SRP concentrations and turbulent diffusivities $(P<0.05)$, but not to water temperatures and daphnid biomasses (Table 4). A smaller bias of maximum mortality term $\left(\begin{array}{ll}d_{\text {cil }} & 0.04 \mathrm{~d}^{-1}\end{array}\right)$ and copepod feeding; MQ (red): ciliate losses as a quadratic mortality term $\left(q_{\mathrm{cil}} \quad 0.0025 \mathrm{~m}^{3} \mathrm{mgC}^{-1} \mathrm{~d}^{-1}\right)$; MR2 (black): ciliates predicted by the linear regression model fitted to log transformed ciliate biomass and chl $a$ concentrations with month specific intercepts. The time of emergence of Daphnia are indicated by dashed lines

ciliate biomass in these models was obtained in years when average SRP concentration was low, and average copepod biomass and turbulent diffusivity were high, as indicated by the sign of the coefficients of these variables (Table 4).

\section{Discussion}

In this study, we developed formulations differing primarily in describing the ciliate mortality mechanisms, and tested the performance of these different models in reproducing the long term field measurements in Lake Constance. The 14 year dataset employed for this purpose, spans 21 years in total, and displays wide range of trophic states characterized by a 10 -fold decrease in winter-phosphorus concentrations (see, e.g., the description of the study site and 
Fig. 5 Same as in Fig. 4 but for algae

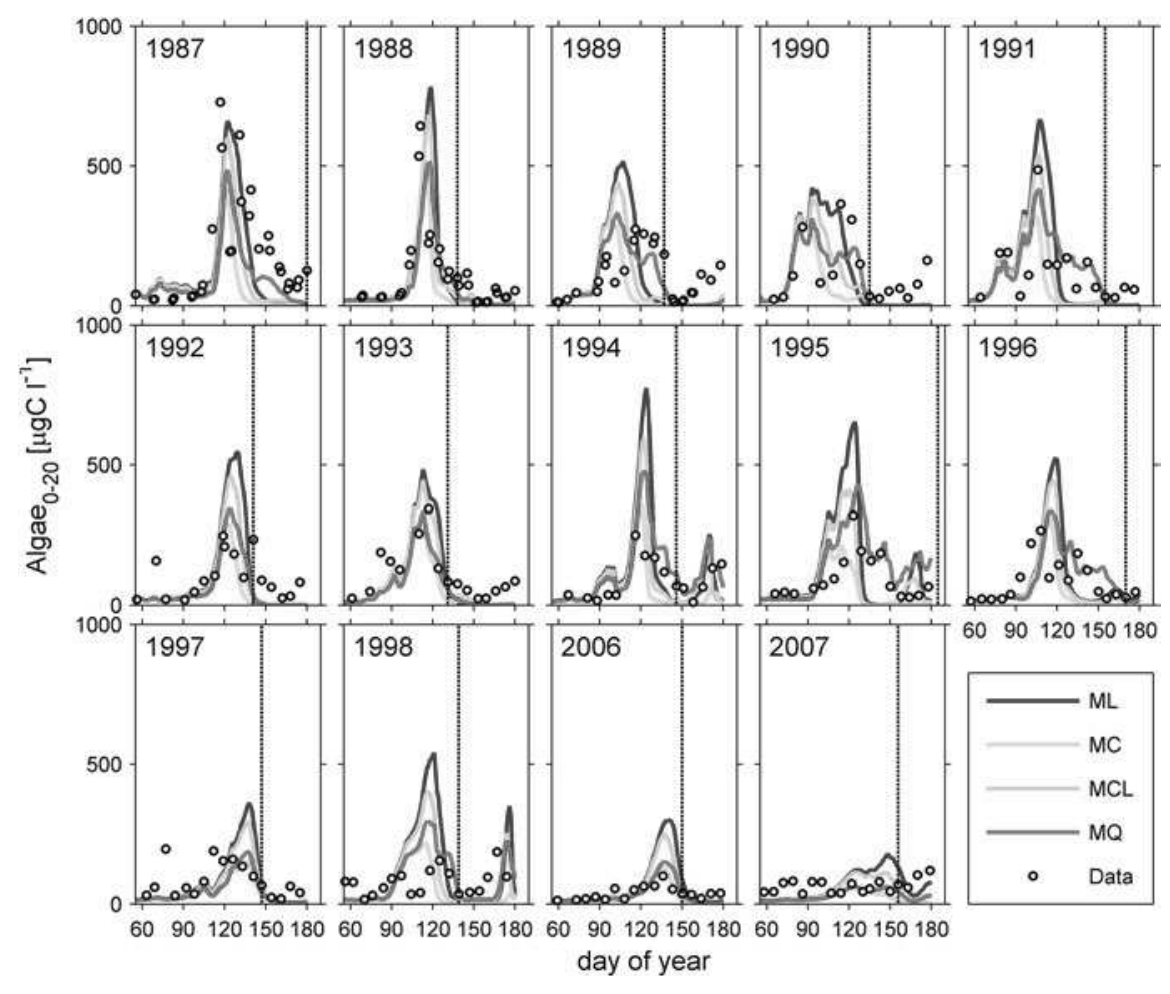

Jochimsen et al., 2013; Stich \& Brinker, 2010) and a variety of climatic conditions (Straile et al., 2010). We evaluated the model performances relative to the performance of a statistical model, which captures the essential features of the observed ciliate dynamics, i.e., the seasonal variation and the long-term decline, hence sets an ambitious test, relative to comparisons of mean values or the natural variances of the predictions and observations (Rykiel, 1996). The model employing a density-dependent mortality rate for ciliates, MQ, not only outperformed the other process-based models, but also the statistical model, especially with regard to the estimation of peak abundances (Fig. 4, Table 2). Therefore, reproduction of the 14 years of observed spring dynamics of algae and ciliates is considered to be satisfactory with the MQ model.

The tight coupling between algae and ciliates (e.g., Irigoien et al., 2005; Tirok \& Gaedke, 2007) allows a reliable estimation of winter-early spring ciliate biomasses via a simple regression approach (MR2). But obviously, the regression model cannot be used to predict future changes in ciliate dynamics, as it depends on prior knowledge of chl $a$ concentrations, which in turn cannot be predicted without considering many factors, notably the physical forcing on the phytoplankton bloom development (Peeters et al., 2007b). The performance of simulation models, and especially of MQ relative to MR2 is remarkable in reproducing the ciliate abundances, given that their predictions depend on a reliable predictions of the hydrodynamical environment and of algal dynamics, which is necessarily hampered by spatial processes such as the displacement of plankton by e.g., internal seiches (e.g., Gaedke \& Schimmele, 1991; Le Vu et al., 2011) that cannot be resolved in a 1D simulation model, whereas the predictive success of the regression model can expected to be less sensitive to such processes as these processes presumably affect the ciliates and phytoplankton similarly.

The apparent inability of ML to capture the algae ciliate dynamics in Lake Constance is not only of practical importance as the linear mortality is the classical closure term in ecosystem models, but it may also provide some insight into the regulation of ciliate dynamics. It should be noted that, this model structure conceptualizes a case in which only an insufficient level of food concentration can result in a negative net rate of change of consumer population. Hence, realization of ciliate peaks requires reduction of algal density below a certain threshold. This threshold algal 
Table 3 Calculated skill scores for each model and for each simulated variable, ciliates and chl $a$

\begin{tabular}{llllrrl}
\hline Variable & Model & $R^{2}$ & NMAE & RMSE & MPEP & MAPEP \\
\hline Ciliates & MQ & 0.52 & 0.77 & 17.34 & 0.05 & 0.29 \\
& ML & 0.32 & 1.30 & 67.50 & 0.96 & 1.22 \\
& MCL & 0.39 & 1.40 & 140.81 & 1.11 & 1.18 \\
& MC & 0.51 & 1.72 & 330.31 & 1.26 & 1.29 \\
Algae & MR2 & 0.75 & 0.50 & 80.00 & 0.52 & 0.52 \\
& MQ & 0.61 & 0.57 & 6.99 & 0.10 & 0.34 \\
& ML & 0.36 & 0.82 & 9.94 & 0.85 & 0.87 \\
& MCL & 0.36 & 0.73 & 7.50 & 0.49 & 0.55 \\
& MC & 0.12 & 0.67 & 36.33 & 0.14 & 0.25 \\
\hline
\end{tabular}

NMAE normalized mean absolute error, MAPE mean absolute percentage error, RMSE root mean square error, MAPEP mean absolute percentage error for spring peak magnitudes, $M P E P$ mean percentage error for spring peak magnitudes. See "Material and methods" section for definitions. For calculating the skill scores, data between day 1 and the emergence of Daphnia for each year in which ciliate data were available, i.e., during 19871998 and 2006 2007, were used ( $n \quad 253$ for algae, $n \quad 220$ for ciliates)

density required for a negative population growth of ciliates according to the ML parameterization not only results in an over-estimation of ciliate populations (Fig. 4) but also in an underestimation of algal densities (Fig. 5), resulting in a misfit with the typically observed coexistence of algae and ciliates until the emergence of Daphnia. The observation that the ciliates, or the microzooplankton in general not causing major crashes of the phytoplankton, as in the case of mesozooplankton causing clear water phases (CWP) appears to be a rather general phenomenon (Irigoien et al., 2005; Sherr \& Sherr, 2009; Sommer et al., 2012).

The copepod feeding model, MC was used to test the potential role of copepods on algae ciliate interactions, and in particular, in controlling the ciliate blooms in Lake Constance. According to the MC, the copepods do not seem to be the main controlling factor of ciliate blooms in Lake Constance. In order to explore the potential of copepods to control ciliates, it was necessary to ensure a strong selection case for ciliates, therefore we set marginal preference values of $p_{\mathrm{cop}, \mathrm{A}}=0.1$ and $p_{\mathrm{cop}, \mathrm{Cil}}=0.9$. The theoretical total grazing rates and dietary fractions resulting from this formulation with the selected parameter values and in situ ranges of prey concentrations is depicted in Fig. 6 panels $\mathrm{c}$ and d, along with a simpler but less- realistic case with constant preferences depicted in panels $\mathrm{a}$ and $\mathrm{b}$ to enable comparison. As the ratio of ciliate density to total food density, fraction of ciliates in diet increases disproportionately, following an S-shaped curve (Fig. 6D) unlike in the constant preference case, where the ratio of the favored food item is always higher (Fig. 6B). This parameterization of the ciliate-preferred active switching behavior of copepods effectively resulted in a higher proportion of ciliates in the copepod diet with the simulated prey concentrations as aimed: according to the MC, during the time period between the chl $a$ onset and the emergence of Daphnia, the average proportion of ciliate carbon biomass in copepod diet ranged from $56 \%$ (in 1993) to $97 \%$ (in 1995) and averaged $76 \%$. Despite this strong selection for ciliates, copepods did not inflict considerable losses to the ciliates sufficient to keep them in check: according to MC simulations, average daily removal rate of ciliates by copepods (Eudiaptomus and cyclopoid copepods) during the time period between the chl $a$ onset and the emergence of Daphnia ranged between 1.1\% (in 2007) to 5.6\% (in 1988) and averaged $2.6 \%$ on average, while the daily in situ population growth rate of ciliates reached to more than $100 \%$ in some years. Considering that a background linear mortality rate in addition to the copepod feeding (MCL) improved the model performance slightly (Table 3 ), the observed algae and ciliate abundances were, however, still not represented as good as by the MQ. The seasonal courses of algae and ciliates simulated by the MCL, which considered a background linear mortality in addition to copepod feeding rate, were better than those produced by the MC, but were still much worse than those obtained by the MQ (Figs. 4, 5).

Copepod feeding parameters employed in this study were based on a detailed laboratory investigation of the nutrition of Cyclops vicinus on a pure algal diet, Chlamydomonas reinhardii (Santer \& van den Bosch, 1994). We employed identical basic feeding parameters, namely, $I_{\text {max,cop }}$ and $K_{\text {cop }}$ (Table 1) for the scenarios in which copepods are feeding either purely on algae (MQ, ML) or selectively on algae and ciliates (MC, MCL). However, whether a switch from suspension feeding of algae to raptorial feeding of ciliates (Kiorboe et al., 1996) would imply changes in the copepod attack rate and handling time in terms of a Holling's function, or in the maximum ingestion rate and half saturation constant in terms of Monod's 
Table 4 Summary of backward regression model statistics relating residuals of predicted ciliates peak biomass to soluble reactive phosphate concentration $(\mathrm{P})$, turbulent diffusion coef ficient (TD) and copepod biomass (COP, cyclopoid copepods + Eudiaptomus), daphnid biomass, and water tem perature, all averaged for the top 20 meters during the bloom period, defined as the onset of algae bloom (chlorophyll $a>3$ $\left.\left[\mu \mathrm{g} 1^{-1}\right]\right)$ and the emergence of Daphnia

\begin{tabular}{llll}
\hline Model & Independent variables & $R^{2}$ & $P$ \\
\hline MQ & & & \\
ML & $\mathrm{P}(+, P<0.05) \mathrm{TD}(, P<0.05) \operatorname{Cop}(, p<0.05)$ & 0.58 & $<0.05$ \\
MCL & $\mathrm{P}(+, P<0.05) \mathrm{TD}(, P<0.05) \operatorname{Cop}(, p<0.05)$ & 0.57 & $<0.05$ \\
MC & $\mathrm{P}(+, P<0.05) \mathrm{TD}(, P<0.05) \operatorname{Cop}(, p<0.05)$ & 0.56 & $<0.05$ \\
\hline
\end{tabular}

Shown are the sign and significance of regression coefficients of the independent variables that remained in the models
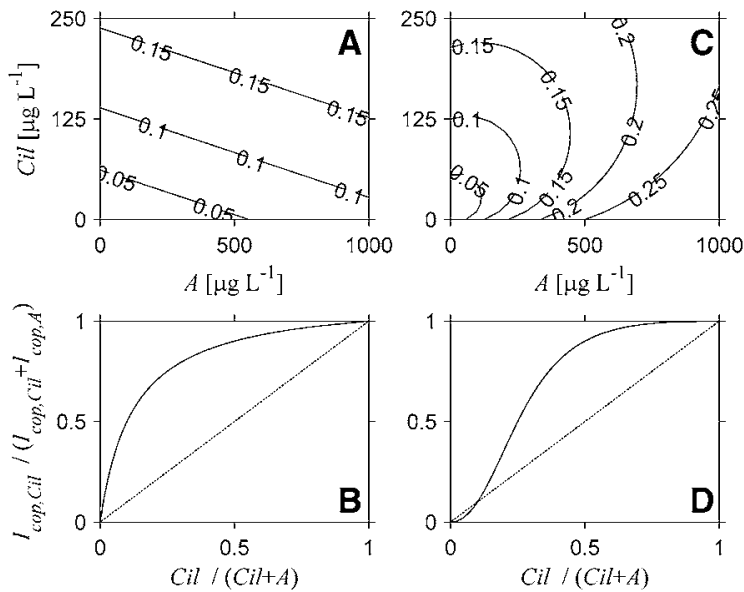

Fig. 6 Functional characteristics of constant preference (A, B) and ratio based preference $(\mathbf{C}, \mathbf{D})$ resource selection schemes, based on the parameterization of copepod feeding on algae, $A$ and ciliates, Cil ( $I_{\max , i} 0.5\left[\mathrm{~d}^{-1}\right], \quad K_{i} \quad 500$ $\left.\left[\mu \mathrm{gC} 1^{-1}\right], p_{\text {cop,A }} \quad 0.1, p_{\text {cop,Cil }} \quad 0.9\right)$. Panels $(\mathbf{A}, \mathbf{C})$ show total ingestion rate $\left(I_{i, \mathrm{Cil}}+I_{i, \mathrm{~A}}\right)\left[\mathrm{d}^{-1}\right]$ over a grid of $A$ and $C i l$ densities covering the range observed in Lake Constance. Panels (B, D) show fraction of ciliate biomass in the diet versus fraction of ciliate biomass concentration in the environment (equal fraction case is shown by the diagonal line for reference). Note that only the ratio based preference scheme was used in the numerical simulations

function (which is formally identical to the Holling's function), is an open question. Although selective feeding experiments suggest that the copepods prefer ciliates over algae when ciliates are present in sufficient abundances (Kiorboe et al., 1996; Gismervik \& Andersen, 1997; Saage et al., 2009), these studies do not focus on the effect of presence of alternative food sources on the feeding parameters. In order to account for this uncertainty, we tested a model scenario where $I_{\text {max,cop }}$ was doubled and $K_{\text {cop }}$ was halved. With the new parameters, simulated algae ciliate dynamics approached to the dynamics simulated by the MQ model (simulations not shown), thus, the observed ranges in most of the years, although there were still several years in which the magnitude of simulated ciliate blooms were substantially higher than the observed blooms. In conclusion, based on our model analysis, it can be argued that feeding by copepods is unlikely to be the main mechanism responsible for the regulation of ciliate biomasses in Lake Constance, even if the copepods strongly prefer ciliates over algae in their diet, but nevertheless feed on ciliates at rates observed on pure algal diet (parameterization of the model MC). However, if the feeding rate of copepods can be shown to be increase substantially upon switching from suspension feeding to raptorial feeding, feeding by copepods can claimed to become a major mechanism responsible for the regulation of ciliate blooms in Lake Constance, at least in most years.

Success of the MQ model is remarkable, especially considering the simplicity of its formulation contrasting with the complex feeding interactions of ciliates. In the MQ model, losses caused by the quadratic mortality term are highly variable throughout the spring season, with specific loss rates starting from near-zero values in early spring and reaching to $0.150 .2 \mathrm{~d}^{-1}$ (corresponding to population loss rates $1020 \mathrm{mgC} \mathrm{m}^{-3} \mathrm{~d}^{-1}$ ) toward the end of spring. There exist several potential regulatory processes that might have been emulated by the losses implied by the density-dependent mortality rate in the MQ model, used here as an empirical tuning parameter. Densitydependent mortality has often been attributed to some unresolved top predator (Steele \& Henderson, 1992; Fasham, 1995) or omnivory within the group (Taylor \& Joint, 1990) in ecosystem models. In this study, we 
confined our analysis to an early time period of the year during which the Daphnia remain in concentrations low enough to be unable to inflict considerable losses to ciliates (Tirok \& Gaedke, 2006), and our explicit treatment of copepod predation on ciliates suggests that the predation pressure by copepods on its own is unlikely to be able to regulate the ciliate bloom (see the "Discussion" section above). In addition to copepods, several other predators might contribute to the overall predation pressure on ciliates including carnivorous ciliates (Stoecker \& Evans, 1985, Müller et al., 1991), rotifers (Arndt, 1993) and even fish larvae (Zingel et al., 2012). However, considering the biomass distribution of potential predators in Lake Constance (Gaedke et al., 2002) is unlikely that one single group will emerge as the main predator on ciliates. Rather, it is the combined predatory impact of different predators, which might finally cause the decline of ciliate biomass. This decline might also be triggered for some ciliate taxa by seasonal changes in life history strategy, i.e., to stop cell division and to start encystment. For example, oligotrich ciliates in Lake Constance were shown to form cycts with estimated encystment rates reaching up to $\sim 14 \%$ percent of the total production rate (Müller \& Wunsch, 1999), thereby contributing to the termination of the ciliate bloom (Tirok \& Gaedke, 2007).

In regulation of ciliates, potential contribution of their interactions with the lower part of the trophic chain should also be considered: Assimilation efficiencies of ciliates were proposed to decrease with increasing ingestion rates (Fenton et al., 2010) and their mortality rates to increase with declining prey abundance (Minter et al., 2011), which can in effect, dampen ciliate blooms. Likewise, the role of food quality in respect to the morphology, stoichiometric, and biochemical composition of algae will be important to consider in future studies. Various techniques are available to account for the role of size in preypredator interactions in ecological models (Ward et al., 2012; Wirtz, 2012), consideration of which was however not of critical importance in this study as the spring phytoplankton community in Lake Constance, even in the most eutrophic period mostly consisted of the small, edible species (Müller et al., 1991; Sommer et al., 1993), as was assumed in this study. Similarly, a model-assisted analysis of the influence of the algal nutrient content on the termination of ciliate blooms can be performed by using a flexible-stoichiometry model (Grover, 2002) or more simply by employing a "stoichiometric modulation of predation" term (Mitra \& Flynn, 2007) and probably necessarily also by considering feeding of ciliates on bacteria (Sherr \& Sherr, 1987) and heterotrophic nanoflagellates (Jürgens et al., 1996), that are typically found in higher nutritional values than the phytoplankton in Lake Constance (Gaedke et al., 2002). Finally, although mixotrophy among the ciliate communities in Lake Constance has not been suggested to be important so far and hence was not considered in this study, mixotrophic groups have been observed to dominant forms in some systems (Modenutti \& Balseiro, 2002, Woelfl \& Geller, 2002, Woelfl, 2007), analysis of which would obviously require consideration of a different conceptual framework (Kooijman et al., 2004, Modenutti \& Balseiro, 2008).

The backward regression model selection suggests that, in regard to various environmental parameters, model formulations other than the MQ are significantly biased. According to the sign of the coefficients of the selected regression models, predictive power of ML, MC, and MCL models for the peak ciliate biomass increased when phosphate concentrations were low, and turbulent diffusivity and copepod grazing pressure were high. In other words, the impaired production of ciliates by a combination of factors anomalously different than the average conditions lead to smaller model-data misfits for these models. Note that this finding is particularly relevant for the modeling practices for which the calibration of parameters are based on a limited time span of measurements that can possibly fail to represent average environmental forcing likely to occur in the study system.

Ecosystem models typically consider a single zooplankton unit, parameterization of which is based on the measurements of single major group, such as the daphnids and copepods. However, microzooplankton, particularly the ciliates are recognized to be an important factor for the control of phytoplankton growth during the early bloom period. Omission of microzooplankton in the ecosystem models and calibration of phytoplankton growth based on algal abundances can potentially lead to underestimation of phytoplankton growth rates, which can lead to misinterpretation of trophic interactions and energy/ nutrient fluxes. On the other hand, understanding of the ecology of microzooplankton is challenged by an 
exceptionally complex network of trophic interactions these organisms are embedded in, and an exact description of such a system in a modeling framework might be aimed in controlled mesocosm experiments as a starting point, but not yet as a part of full pelagic ecosystem models to reproduce the field measurements in our view. In this study, we have shown that, parameterization of a density-dependent mortality rate as a loss term enables simulation of ciliate blooms during spring in a wide variety of environmental conditions, thus, potentially offering a convenient way for resolving the microzooplankton in ecosystem models, which can in turn, serve in understanding the functioning of other components of the ecosystem, such as the regulation of phytoplankton (Kerimoglu et al., 2013). Our study also demonstrates that, if the sole purpose is to predict the ciliate abundances during spring, a simple liner regression from algal abundances may suffice, as long as a high-resolution training dataset is available.

Acknowledgments The long term data were mostly sampled within the DFG funded Special Collaborative Programme 248 ("Cycling of matter in Lake Constance"). Meteorological data were gifted by the German Meteorological Service (Deutscher Wetterdienst). The authors thank H. Rossknecht (Institut für Seenforschung, Langenargen) for providing SRP concentrations. Funding was provided by the Deutsche Forschungsgemeinschaft (DFG) within the AQUASHIFT programme (SPP 1162, PE $701 / 2$ 2). The authors thank Peeter Noges and two anonymous reviewers for their helpful comments.

\section{References}

Adrian, R. \& B. Schneider Olt, 1999. Top down effects of crustacean zooplankton on pelagic microorganisms in a mesotrophic lake. Journal of Plankton Research 21(11): 21752190.

Alewell, C. \& B. Manderscheid, 1998. Use of objective criteria for the assessment of biogeochemical ecosystem models. Ecological Modelling 107(2 3): 213224.

Arndt, H., 1993. Rotifers as predators on components of the microbial web (bacteria, heterotrophic flagellates, ciliates) a review. Hydrobiologia 255: 231246.

Baretta, J. W., W. Ebenhoh \& P. Ruardij, 1995. The European Regional Seas Ecosystem Model, a complex marine eco system model. Netherlands Journal of Sea Research 33: 233246.

Beaver, J. R. \& T. L. Crisman, 1989. The role of ciliated pro tozoa in pelagic fresh water ecosystems. Microbial Ecol ogy 17: 111136.

Berk, S. G., D. C. Brownlee, D. R. Heinle, H. J. Kling \& R. R. Colwell, 1977. Ciliates as a food source for marine planktonic copepods. Microbial Ecology 4: 2740.
Blackford, J. C., J. I. Allen \& F. J. Gilbert, 2004. Ecosystem dynamics at six contrasting sites: a generic modelling study. Journal of Marine Systems 52: 191215.

Bruce, L. C., D. Hamilton, J. Imberger, G. Gal, M. Gophen, T. Zohary \& K. D. Hambright, 2006. A numerical simulation of the role of zooplankton in $\mathrm{C}, \mathrm{N}$ and $\mathrm{P}$ cycling in Lake Kinneret, Israel. Ecological Modelling 193: 412436.

Buitenhuis, E. T., R. B. Rivkin, S. Sailley \& C. Le Quere, 2010. Biogeochemical fluxes through microzooplankton. Global Biogeochemical Cycles 24: Gb4015.

Calbet, A., 2008. The trophic roles of microzooplankton in marine systems. ICES Journal of Marine Sciences 65: 325331.

Calbet, A. \& M. R. Landry, 2004. Phytoplankton growth, mi crozooplankton grazing, and carbon cycling in marine systems. Limnology and Oceanography 49: 5157.

Calbet, A. \& E. Saiz, 2005. The ciliate copepod link in marine ecosystems. Aquatic Microbial Ecology 38: 157167.

Dolan, J. R. \& D. W. Coats, 1991. A study of feeding in pre dacious ciliates using prey ciliates labeled with fluorescent microspheres. Journal of Plankton Research 13: 609627.

Edwards, A. M. \& A. Yool, 2000. The role of higher predation in plankton population models. Journal of Plankton Research 22: 10851112.

Fasham, M. J. R., 1995. Variations in the seasonal cycle of biological production in sub Arctic oceans a model sensitivity analysis. Deep Sea Research Part I Oceano graphic Research Papers 42: 11111149.

Fasham, M. J. R., H. W. Ducklow \& S. M. McKelvie, 1990. A nitrogen based model of plankton dynamics in the oceanic mixed layer. Journal of Marine Research 48: 591639.

Fennel, W. \& T. Neumann, 1996. The mesoscale variability of nutrients and plankton as seen in a coupled model. German Journal of Hydrology 48: 4971.

Fenton, A., M. Spencer \& D. J. S. Montagnes, 2010. Para meterising variable assimilation efficiency in predator prey models. Oikos 119: 10001010.

Gaedke, U. \& M. Schimmele, 1991. Internal seiches in Lake Constance influence on plankton abundance at a fixed sampling site. Journal of Plankton Research 13: 743754.

Gaedke, U., S. Hochstadter \& D. Straile, 2002. Interplay between energy limitation and nutritional deficiency: empirical data and food web models. Ecological Mono graphs 72: 251270

Geider, R. J. \& B. A. Osborne, 1989. Respiration and microalgal growth: a review of the quantitative relationship between dark respiration and growth. New Phytologist 112: 327341.

Geller, W. \& H. Müller, 1985. Seasonal variability in the rela tionship between body length and individual dry weight as related to food abundance and clutch size in two coexisting Daphnia species. Journal of Plankton Research 7: 118.

Gentleman, W., A. Leising, B. Frost, S. Strom \& J. Murray, 2003. Functional responses for zooplankton feeding on multiple resources: a review of assumptions and biological dynamics. Deep Sea Research Part II Topical Studies in Oceanography 50: 28472875.

Gismervik, I. \& T. Andersen, 1997. Prey switching by Acartia clausi: experimental evidence and implications of intra guild predation assessed by a model. Marine Ecology Progress Series 157: 247259. 
Goudsmit, G. H., H. Burchard, F. Peeters \& A. Wuest, 2002. Application of $\mathrm{k}$ epsilon turbulence models to enclosed basins: the role of internal seiches. Journal of Geophysical Research Oceans 107: 32303242.

Grover, J. P., 2002. Stoichiometry, herbivory and competition for nutrients: simple models based on planktonic ecosys tems. Journal of Theoretical Biology 214: 599618 .

Hansen, P. J., P. K. Bjornsen \& B. W. Hansen, 1997. Zoo plankton grazing and growth: scaling within the 22,000 $\mu \mathrm{m}$ body size range. Limnology and Oceanography 42 : 687704.

Häse, C., 1996. Die Vorhersage der Produktivität des Phyto planktons im Bodensee unter Berücksichtigung der Tem peratur sowie der spektralen Zuzammensetzung des Unterwasser Strahlungsfeldes. Universität Konstanz.

Häse, C., U. Gaedke, S. A., B. Beese \& M. M. Tilzer, 1998. Phytoplankton response to re oligotrophication in large and deep Lake Constance: photosynthetic rates and chlo rophyll concentrations. Arch Hydrobiol Spec Issues: Advances in Limnology 53:159 178.

Irigoien, X., K. J. Flynn \& R. P. Harris, 2005. Phytoplankton blooms: a 'loophole' in microzooplankton grazing impact? Journal of Plankton Research 27(4): 313321.

Janssen, P. H. M. \& P. S. C. Heuberger, 1995. Calibration of process oriented models. Ecological Modelling 83(1 2): 5566.

Jassby, A. D. \& T. Platt, 1976. Mathematical formulation of relationship between photosynthesis and light for phyto plankton. Limnology and Oceanography 21(4): 540547.

Jochimsen, M. C., R. Kümmerlin \& D. Straile, 2013. Com pensatory dynamics and the stability of phytoplankton biomass during four decades of eutrophication and oligo trophication. Ecology Letters 16: 8189 .

Jürgens, K., S. A. Wickham, K. O. Rothhaupt \& B. Santer, 1996. Feeding rates of macro and microzooplankton on hetero trophic nanoflagellates. Limnology and Oceanography 41: 18331839.

Jürgens, K., O. Skibbe \& E. Jeppesen, 1999. Impact of meta zooplankton on the composition and population dynamics of planktonic ciliates in a shallow, hypertrophic lake. Aquatic Microbial Ecology 17: 6175.

Kerimoglu, O., D. Straile \& F. Peeters, 2013. Seasonal, inter annual and long term variation in top down versus bot tom up regulation of primary production. Oikos 122: 223234

Kiorboe, T., E. Saiz \& M. Viitasalo, 1996. Prey switching behaviour in the planktonic copepod Acartia tonsa. Marine Ecology Progress Series 143: 6575.

Kleppel, G. S., 1993. On the diets of calanoid copepods. Marine Ecology Progress Series 99: 183195.

Kooijman, S., T. Andersen \& B. W. Kooi, 2004. Dynamic energy budget representations of stoichiometric constraints on population dynamics. Ecology 85: 12301243

Landry, M. R., 1981. Switching between herbivory and carni vory by the planktonic marine copepod Calanus pacificus. Marine Biology 65: 7782.

Le Vu, B., B. Vincon Leite, B. J. Lemaire, N. Bensoussan, M. Calzas, C. Drezen, J. F. Deroubaix, N. Escoffier, Y. Degres, C. Freissinet, A. Groleau, J. F. Humbert, G. Paolini, F. Prevot, C. Quiblier, E. Rioust \& B. Tassin, 2011. High frequency monitoring of phytoplankton dynamics within the European water framework directive: application to metalimnetic cyanobacteria. Biogeochemistry 106: 229242.

MacIntyre, S. \& J. M. Melack, 1995. Vertical and horizontal transport in lakes: linking littoral, benthic, and pelagic habitats. Journal of the North American Benthological Society 14: 599615.

Minter, E. J. A., A. Fenton, J. Cooper \& D. J. S. Montagnes, 2011. Prey dependent mortality rate: a critical parameter in microbial models. Microbial Ecology 62: 155161.

Mitra, A. \& K. J. Flynn, 2007. Importance of interactions between food quality, quantity, and gut transit time on consumer feeding, growth, and trophic dynamics. Ameri can Naturalist 169: 632646.

Modenutti, B.E. \& E. G. Balseiro, 2002. Mixotrophic ciliates in an Andean lake: dependence on light and prey of an Ophrydium naumanni population. Freshwater Biology 47: 121128.

Modenutti, B. E. \& E. G. Balseiro, 2008. Light versus food supply as factors modulating niche partitioning in two pelagic mixotrophic ciliates. Limnology and Oceanogra phy 53: 446455 .

Montagnes, D. J. S. \& E. J. Lessard, 1999. Population dynamics of the marine planktonic ciliate Strombidinopsis multiau ris: its potential to control phytoplankton blooms. Aquatic Microbial Ecology 20: 167181.

Müller, H., 1989. The relative importance of different ciliate taxa in the pelagic food web of Lake Constance. Microbial Ecology 18: 261273.

Müller, H. \& C. Wunsch, 1999. Seasonal dynamics of cyst formation of pelagic strombidiid ciliates in a deep preal pine lake. Aquatic Microbial Ecology 17: 3747.

Müller, H., A. Schoene, R. M. Pinto Coelho, A. Schweizer \& T. Weisse, 1991. Seasonal succession of ciliates in Lake Constance. Microbial Ecology 21: 119138.

Murdoch, W. W., 1969. Switching in general predators. Experiments on predator specificity and stability of prey populations. Ecological Monographs 39:335 \&.

Pace, M. L. \& J. D. Orcutt, 1981. The relative importance of protozoans, rotifers and crustaceans in a fresh water zoo plankton community. Limnology and Oceanography 26: 822830 .

Peeters, F., D. M. Livingstone, G. H. Goudsmit, R. Kipfer \& R. Forster, 2002. Modeling 50 years of historical temperature profiles in a large central European lake. Limnology and Oceanography 47: 186197.

Peeters, F., D. Straile, A. Lorke \& D. M. Livingstone, 2007a. Earlier onset of the spring phytoplankton bloom in lakes of the temperate zone in a warmer climate. Global Change Biology 13: 18981909.

Peeters, F., D. Straile, A. Lorke \& D. Ollinger, 2007b. Turbulent mixing and phytoplankton spring bloom development in a deep lake. Limnology and Oceanography 52: 286298.

Rossknecht, H., 1998. Langjahrige entwicklung chemischer parameter im bodensee obersee. Bericht/Internationale Gewasserschutzkommission für den Bodensee 48: 1137.

Rykiel, E. J., 1996. Testing ecological models: the meaning of validation. Ecological Modelling 90: 229244.

Saage, A., O. Vadstein \& U. Sommer, 2009. Feeding behaviour of adult Centropages hamatus (Copepoda, Calanoida): functional response and selective feeding experiments. Journal of Sea Research 62: 1621 . 
Santer, B. \& F. van den Bosch, 1994. Herbivorous nutrition of Cyclops vicinus: the effect of a pure algal diet on feeding, development, reproduction and life cycle. Journal of Plankton Research 16: 171195.

SAS Institute Inc., 2004 SAS 9.1.3 Help and Documentation. Cary: SAS Institute, Inc.

Scheffer, M. \& R. J. De Boer, 1995. Implications of spatial heterogeneity for the paradox of enrichment. Ecology 76: 22702277.

Sherr, E. B. \& B. F. Sherr, 1987. High rates of consumption of bacteria by pelagic ciliates. Nature 325: 710711

Sherr, E. B. \& B. F. Sherr, 2009. Capacity of herbivorous pro tists to control initiation and development of mass phyto plankton blooms. Aquatic Microbial Ecology 57: 253262.

Smayda, T. J., 1997. Harmful algal blooms: their ecophysiology and general relevance to phytoplankton blooms in the sea. Limnology and Oceanography 42: 11371153.

Sommer, U., 1984. Sedimentation of principal phytoplankton species in Lake Constance. Journal of Plankton Research 6: 114.

Sommer, U., Z. M. Gliwicz, W. Lampert \& A. Duncan, 1986. The PEG model of seasonal succession of planktonic events in fresh waters. Archiv Für Hydrobiologie 106: 433471.

Sommer, U., U. Gaedke \& A. Schweizer, 1993. The 1st decade of oligotrophication of lake constance. 2. The response of phytoplankton taxonomic composition. Oecologia 93: 276284.

Sommer, U., R. Adrian, L. N. D. Domis, J. J. Elser, U. Gaedke, B. W. Ibelings, E. Jeppesen, M. Lürling, J. C. Molinero, W. M. Mooij, E. van Donk \& M. Winder, 2012. Beyond the Plankton Ecology Group (PEG) model: mechanisms driv ing plankton succession. Annual Review of Ecology, Evolution and Systematics 43: 429448.

Steele, J. H. \& E. W. Henderson, 1992. The role of predation in plankton models. Journal of Plankton Research 14: 157172

Stich, H. B. \& A. Brinker, 2010. Oligotrophication outweighs effects of global warming in a large, deep, stratified lake ecosystem. Global Change Biology 16: 877888.

Stoecker, D. K. \& J. M. Capuzzo, 1990. Predation on protozoa: its importance to zooplankton. Journal of Plankton Research 12: 891908.

Stoecker, D. K. \& G. T. Evans, 1985. Effects of protozoan herbivory and carnivory in a microplankton food web. Marine Ecology Progress Series 25: 159167.

Straile, D., 1997. Gross growth efficiencies of protozoan and metazoan zooplankton and their dependence on food con centration, predator prey weight ratio, and taxonomic group. Limnology and Oceanography 42: 13751385.

Straile, D., O. Kerimoglu, F. Peeters, M. C. Jochimsen, R. Kummerlin, K. Rinke \& K. O. Rothhaupt, 2010. Effects of a half a millennium winter on a deep lake a shape of things to come? Global Change Biology 16: 28442856.

Strom, S. L. \& T. A. Morello, 1998. Comparative growth rates and yields of ciliates and heterotrophic dinoflagellates. Journal of Plankton Research 20: 571584.

Taylor, A. H. \& I. Joint, 1990. A steady state analysis of the microbial loop in stratified systems. Marine Ecology Pro gress Series 59: 117.
Tilzer, M. M., 1988. Secchi disk chlorophyll relationships in a lake with highly variable phytoplankton biomass. Hydro biologia 162: 163171.

Tirok, K. \& U. Gaedke, 2006. Spring weather determines the relative importance of ciliates, rotifers and crustaceans for the initiation of the clear water phase in a large, deep lake. Journal of Plankton Research 28: 361373.

Tirok, K. \& U. Gaedke, 2007. Regulation of planktonic ciliate dynamics and functional composition during spring in Lake Constance. Aquatic Microbial Ecology 49: 87100.

Ward, B. A., S. Dutkiewicz, O. Jahn \& J. Follows, 2012. A size structured food web model for the global ocean. Limnol ogy and Oceanography 57: 18771891 .

Weglarczyk, S., 1998. The interdependence and applicability of some statistical quality measures for hydrological models. Journal of Hydrology 206: 98103.

Weisse, T., 1991. The annual cycle of heterotrophic fresh water nanoflagellates: role of bottom up and top down control. Journal of Plankton Research 13: 167185.

Weisse, T., 2006. Freshwater ciliates as ecophysiological model organisms lessons from Daphnia, major achievements, and future perspectives. Archiv Für Hydrobiologie 167: 371402.

Weisse, T., H. Müller, R. M. Pintocoelho, A. Schweizer, D. Springmann \& G. Baldringer, 1990. Response of the microbial loop to the phytoplankton spring bloom in a large prealpine lake. Limnology and Oceanography 35: 781794.

Weisse, T., N. Karstens, V. C. L. Meyer, L. Janke, S. Lettner \& K. Teichgraber, 2001. Niche separation in common pros tome freshwater ciliates: the effect of food and tempera ture. Aquatic Microbial Ecology 26: 167179.

Wickham, S. A., 1995. Trophic relations between cyclopoid copepods and ciliated protists: complex interactions link the microbial and classic food webs. Limnology and Oceanography 40: 11731181.

Wickham, S. A. \& J. J. Gilbert, 1993. The comperative impor tance of competition and predation by Daphnia on ciliated protists. Archiv Für Hydrobiologie 126: 289313.

Wirtz, K. W., 2012. Who is eating whom? Morphology and feeding type determine the size relation between plank tonic predators and their ideal prey. Marine Ecology Pro gress Series 445: 112.

Woelfl, S., 2007. The distribution of large mixotrophic ciliates (Stentor) in deep North Patagonian lakes (Chile): first results. Limnologica 37: 2836.

Woelfl, S. \& W. Geller, 2002. Chlorella bearing ciliates domi nate in an oligotrophic North Patagonian lake (Lake Pire hueico, Chile): abundance, biomass and symbiotic photosynthesis. Freshwater Biology 47: 231242.

Wölfl, S., 1991. The pelagic copepod species in Lake Con stance: abundance, biomass, and secondary productivity. Verhandlungen des Internationalen Verein Limnologie 24: 854857.

Zingel, P., T. Paaver, K. Karus, H. Agasild \& T. Noges, 2012. Ciliates as the crucial food source of larval fish in a shallow eutrophic lake. Limnology and Oceanography 57: 1049 1056. 